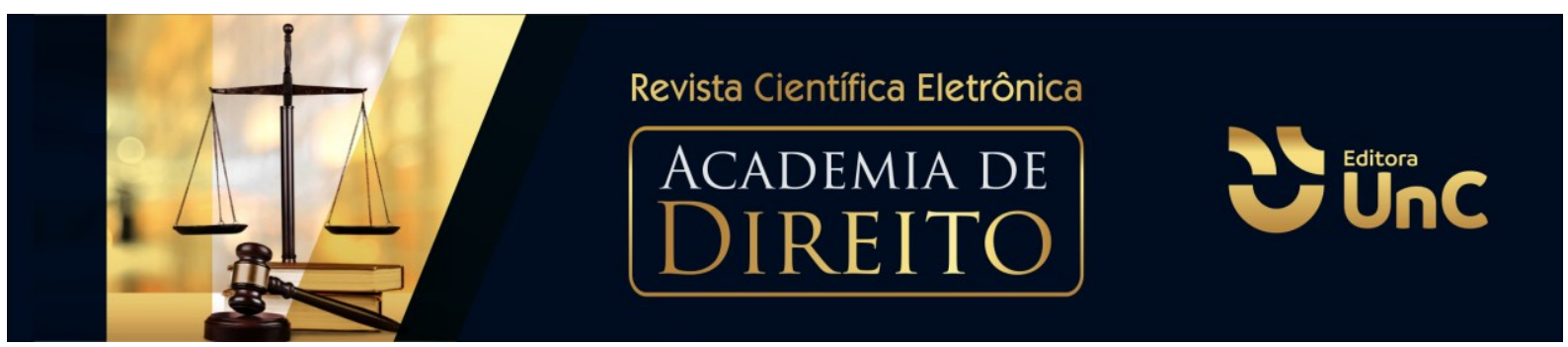

\title{
A NECESSIDADE DE PADRONIZAÇÃO DO PROCESSO DE COMPRAS NA ASSOCIAÇÃO CATARINENSE DAS FUNDAÇÕES EDUCACIONAIS (ACAFE)
}

\section{THE NEED FOR STANDARDIZATION OF THE PURCHASING PROCESS IN ASSOCIAÇÃO CATARINENSE DAS FUNDAÇÕES EDUCACIONAIS (ACAFE)}

Luiz Gustavo Grahl de Souza ${ }^{1}$

\begin{abstract}
RESUMO
O presente trabalho tem por objetivo principal a padronização do processo de compras de bens e serviços na Associação Catarinense das Fundações Educacionais - ACAFE. Através de pesquisas e coletas de dados, ficou claro que as fundações coligadas não obedecem um sistema integrado e legalizado para as aquisições de bens e serviços, fazendo com isso despertar o interesse em desenvolver 0 trabalho de monografia, tratando desse tema, tão importante, polêmico e pouco debatido. Com a conclusão desse artigo, o autor tem como premissa apresentar o presente trabalho, provocando o debate dentro das câmaras setoriais do sistema ACAFE, e deixar como opção o grande interesse na padronização dos processos dentro das legalidades em observância as leis aplicáveis, fazendo com isso que o processo se torne uno, ágil, econômico, representando ao seu final a segurança jurídica social de que o processo obedece premissas assecuratória instrumentais.
\end{abstract}

Palavras-chave: Compras. Processo. ACAFE. Legalidade. Sustentabilidade.

\begin{abstract}
The present work has as main objective the standardization of the process of purchasing goods and services in the Santa Catarina Association of Educational Foundations - ACAFE. Through research and data collection, it has become clear that related foundations do not follow an integrated and legalized system for the acquisition of goods and services, thus arousing interest in developing monograph work, addressing this very important, controversial subject. and little debated. With the conclusion of this article, the author's premise is to present the present work, provoking debate within the sectoral chambers of the ACAFE system, and leaving as an option the great interest in the standardization of processes within the legalities in
\end{abstract} ${ }^{1}$ Graduando em Direito. Universidade do Contestado (UnC). Campus Mafra. Santa Catarina. Brasil. E-
mail: gustavo.juridico@unc.br 
compliance with applicable laws, making it that the process becomes one, agile, economic, representing at its end the social legal certainty that the process obeys instrumental assecuratory premises.

Keywords: Purchasing. Process. ACAFE. Legality. Sustainability.

\section{INTRODUÇÃO}

Nos departamentos de compras das unidades educacionais, devido principalmente as atividades intensas, ocorrem uma série de dificuldades que afetam diretamente o cotidiano de trabalho.

Através de pesquisas, foram detectadas grandes dificuldades do departamento de compras das universidades coligadas que fazem parte da Associação Catarinense das Fundações Educacionais (ACAFE) como:

- Falta de procedimento único em todo o sistema associado: nota-se que existem várias universidades de Santa Catarina inseridas na mesma plataforma chamada ACAFE, entretanto cada uma faz da sua maneira e como melhor convier a operacionalização do sistema de Compras.

A presente pesquisa tem como proposta investigar e identificar os principais fatores que contribuem para o sucesso do processo de compras padronizadas e unificadas em todo o sistema ACAFE, à partir de análise criteriosa à luz do Ordenamento Jurídico Brasileiro e de procedimentos administrativos à praticar pelos departamentos envolvidos.

O trabalho está dividido em 04 (quatro) capítulos, na qual o primeiro tem como objeto de estudo a evolução e a proposta da pesquisa. No segundo, serão apresentadas as linhas de referencias, definição e modalidades dos processos licitatórios. Já o terceiro capítulo aborda metodologias do estudo do caso. No último capítulo serão apresentadas as considerações finais.

O setor de compras é responsável por todas as compras de materiais, bens e serviços, atendendo todos os setores das organizações. O departamento ideal deverá ser constituído por um Gerente Geral de Compras, Assistentes e auxiliares.

O departamento desenvolve todos os tipos de compras necessárias para a instituição, que são desde as compras de materiais mais simples como as de expediente, consumo e limpeza, até as mais complexas como as de construção civil, 
veículos, etc. Os procedimentos de compras, devem ser regidos de acordo com Instruções Normativas.

O presente estudo tem como objetivos específicos elencar premissas como: adquirir bens e serviços na legalidade vigente, na qualidade desejada, no momento preciso, pelo menor custo possível e na quantidade pedida, entre elas, enumeram os seguintes pontos:

1) adquirir bens e serviços: são adquiridos para atender a necessidade dos setores, que podem ser materiais de expediente ou equipamentos como computadores, impressoras, móveis, livros para a biblioteca, equipamentos para laboratórios, etc. São contratados também serviços como os outsourcing de impressão, construção civil, manutenções e serviços gerais, etc.

2) na legalidade vigente: para que o processo seja realizado dentro das legalidades necessárias, devemos observar as leis vigentes em nosso país e propor o cumprimento das mesmas.

3) na qualidade desejada: quando são feitas as requisições de compras, o setor precisa comprar o material ou serviço de acordo com as especificações descritas pelo requisitante evitando que a aquisição não corresponda à necessidade, tornando a compra num mau negócio, ao mesmo tempo que cause o descontentamento do requisitante.

4) no momento preciso: o setor precisa cuidar para que as aquisições principalmente de alguns materiais ou contratação de alguns serviços, sejam efetuados em tempo real, de acordo com a necessidade do requisitante. Em alguns casos, a cadeia de serviços nos setores pode ser interrompida pela falta de algum material ou serviço necessário. Podendo o departamento de compras ser responsabilizado por prejudicar o desempenho da empresa.

5) pelo menor custo possível: cabe ao departamento de compras buscar, obrigatoriamente, o menor custo possível para a aquisição do produto ou contratação do serviço (saving). Procurar sempre pela melhor proposta de valores é essencial para o setor, pela qual está sempre à procura dos melhores fornecedores e na busca incessante pelos menores preços. 
6) na quantidade pedida: atender a demanda solicitada tentando otimizar produtos/serviços da mesma família, evitando assim o pagamento desnecessário de fretes, diminuído custos operacionais do setor.

\section{LINHAS DE REFERÊNCIA PARA AS COMPRAS DA ACAFE - DEFINIÇÃO E MODALIDADES}

O termo Compras pode ser definido como a aquisição de um produto ou serviço, pelo qual se paga determinado preço (GARCIA, 2019). As atividades de compras envolvem uma série de fatores como legalidade dos processos, seleção de fornecedores, qualificação dos serviços, determinação de prazos de vendas, previsão de preços, serviços e mudanças na demanda, entre outros. A administração de compras é uma atividade fundamental para uma gestão eficaz das empresas e que influencia diretamente nos seus estoques e no relacionamento com os clientes, estando também relacionada à competitividade e ao sucesso da organização. A aquisição de produtos e serviços representa um fator decisivo na atividade de uma empresa, pois podem gerar redução nos custos e melhorias consideráveis nos lucros, destarte disso, desenvolveu-se este trabalho junto às Fundações do sistema ACAFE - Associação Catarinense das Fundações

\section{Educacionais.}

Em 1974, os presidentes das fundações criadas por lei municipal e da fundação criada pelo Estado constituíram a ACAFE (Associação Catarinense das Fundações Educacionais), entidade sem fins lucrativos, com a missão de promover a integração dos esforços de consolidação das instituições de ensino superior por elas mantidas, de executar atividades de suporte técnico-operacional e de representá-las junto aos órgãos dos Governos Estadual e Federal. Uma de suas principais importâncias para o estado de Santa Catarina está em desenvolver o ensino, ciência, tecnologia e inovação pelo compartilhamento de ações e competências para assegurar o fortalecimento das IES associadas em prol da educação superior em todo o estado (SISTEMA ACAFE, 2019). 


\title{
2.1 LICITAÇÃO E SUAS MODALIDADES
}

Licitação é o "procedimento administrativo pelo qual a Administração Pública, no exercício da sua função administrativa, abre aos interessados a possibilidade de apresentação de propostas, dentre as quais selecionará a mais vantajosa para a celebração de um contrato" (BITTENCOURT, 2001, p. 18). Meirelles, Azevedo e Prendes (1991) afirma, ainda, que licitação é o procedimento administrativo mediante o qual a Administração Pública seleciona a proposta mais vantajosa para o contrato de seu interesse.

A licitação, segundo o artigo $3^{\circ}$, da Lei 8.666/93,

\begin{abstract}
Destina-se a garantir a observância do princípio constitucional da isonomia e a selecionar a proposta mais vantajosa para a Administração e será processada e julgada em estrita conformidade com os princípios básicos da legalidade, da impessoalidade, da moralidade, da igualdade, da publicidade, da probidade administrativa, da vinculação ao instrumento convocatório, do julgamento objetivo e dos que lhes são correlatos (BRASIL, 1993).
\end{abstract}

Segundo o sítio do Portal de Compras,

\begin{abstract}
Uma licitação é uma competição entre empresas interessadas em fornecer algum produto ou serviço que o governo precisa. A empresa que conseguir apresentar as melhores condições e o melhor preço, vence, firma um contrato com o governo e torna-se fornecedora por um período de tempo. Este processo é necessário para padronizar e organizar as compras públicas, afinal o governo tem uma grande responsabilidade na administração de gastos (BRASIL, 2019).
\end{abstract}

A Lei 8.666/93, em seu artigo 22, estabelece que são modalidades de licitação a concorrência, a tomada de preços, o convite, o concurso e o leilão. No entanto, a Lei 10.520/2002 vem estabelecer no âmbito da União, Estados, Distrito Federal e Municípios, a 25 modalidades de licitação denominada Pregão. Portanto, pode-se dizer que 06 (seis) são as modalidades de licitação existentes.

\subsubsection{Concorrência}

Conforme redação do parágrafo primeiro do artigo 22 da Lei 8.666/93, "concorrência é a modalidade de licitação entre quaisquer interessados que, na fase 
inicial de habilitação preliminar, comprovem possuir os requisitos mínimos de qualificação exigidos no edital para execução de seu objeto" (BRASIL, 1993). Meirelles, Azevedo e Prendes (1991) acrescenta que é a modalidade de licitação própria para contratos de grande valor, em que se admite a participação de quaisquer interessados, registrados ou não, que satisfaçam a condição do edital, convocados com antecedência mínima de 30 (trinta) dias. "A concorrência se destina a transações de grande vulto, sendo por este motivo que a publicidade é mais ampla e podem participar do certame quaisquer interessados" (BITTENCOURT, 2001, p. 29)

Segundo o parágrafo terceiro do artigo 22 da Lei 8.666/93, a prática da concorrência é obrigatória, independentemente do valor do contrato, nas seguintes hipóteses estabelecidas: Na compra de bens imóveis; Nas alienações de bens imóveis para as quais não se haja adotado a modalidade leilão, imóveis cujas aquisições derivaram de procedimentos judiciais ou de dação em pagamento; Nas concessões de direito real de uso; e nas licitações internacionais.

\subsubsection{Tomada de Preços}

Conforme Bittencourt (2001) ensina que a tomada de preços objetiva transações de vulto razoável, portanto existe um menor prazo de publicidade e restrições quanto à participação apenas de interessados previamente cadastrados. Enfatiza-se, ainda, que a "tomada de preços é a licitação para contratos de valor estimado imediatamente inferior ao estabelecido para a concorrência, realizada entre interessados previamente cadastrados, observada a necessária qualificação" Meirelles, Azevedo e Prendes (1991).

\subsubsection{Convite}

Segundo Bittencourt (2001) o convite refere-se a transações que envolvem menores valores sendo, dessa forma, bem mais simples que as demais.

É a modalidade de licitação entre interessados do ramo pertinente ao seu objeto, cadastrados ou não, escolhidos e convidados em número mínimo de 3 (três) pela unidade administrativa, a qual afixará, em local apropriado, 
cópia do instrumento convocatório e o estenderá aos demais cadastrados na correspondente especialidade que manifestarem seu interesse com antecedência de até 24 (vinte e quatro) horas da apresentação das propostas (BRASIL, 1993).

Tolosa Filho e Saito (1995) ensinam que o convite dispensa a publicação em diário oficial ou jornal de grande circulação, uma vez que o licitante, cadastrado ou não, escolhido pela unidade administrativa, receberá cópia do mesmo e passará obrigatoriamente recibo. Como não há obrigatoriedade de divulgação da carta convite pela imprensa é suficiente a afixação do mesmo em local próprio da repartição. "Só é válido o convite quando se apresentam, no mínimo, três licitantes qualificados, isto é, e, condições de contratar com a Administração" (MEIRELLES; AZEVEDO; PRENDES, 1991).

Para as obras e serviços de engenharia o valor é de até $R \$ 330.000,00$ (trezentos e trinta mil reais) e para compras e demais serviços o valor é de até $R \$$ $176.000,00$ (cento e setenta e seis mil reais).

\subsubsection{Concurso}

Bittencourt (2001) ensina que o concurso é uma disputa para escolha de trabalho técnico, científico ou artístico, com a instituição de prêmio ou remuneração ao vencedor, com base em critério estabelecido no edital.

Concurso é a modalidade de licitação entre quaisquer interessados para escolha de trabalho técnico, científico ou artístico, mediante a instituição de prêmios ou remuneração aos vencedores, conforme critérios constantes de edital publicado na imprensa oficial com antecedência mínima de 45 (quarenta e cinco) dias (BRASIL, 1993).

Afirma-se, ainda, que o

concurso é uma modalidade de licitação, mas de natureza especial, bem diversificada das demais. Rege-se, é certo, pelos princípios da publicidade e da igualdade entre os participantes, objetivando a escolha do melhor trabalho, mas dispensa as formalidades específicas da concorrência (MEIRELLES; AZEVEDO; PRENDES, 1991).

Meirelles, Azevedo e Prendes (1991) salienta que o regulamento do concurso é que indicará a qualificação exigida dos participantes; estabelecerá as diretrizes e a 
forma de apresentação do trabalho; fixará as condições de sua realização e os prêmios a serem concedidos; designará a Comissão Julgadora e disporá sobre os critérios de julgamento.

\title{
2.1.5 Leilão
}

Leilão, conforme definido pelo parágrafo quinto do artigo 22 e artigo 53 da lei 8.666/93,

\begin{abstract}
É a modalidade de licitação entre quaisquer interessados para a venda de bens móveis inservíveis para a Administração ou de produtos legalmente apreendidos ou penhorados, ou para a alienação de bens imóveis a quem oferecer o maior lance, igual ou superior ao valor de avaliação (BRASIL, 1993).
\end{abstract}

Segundo Bittencourt (2001), o leilão refere-se à venda de bens e serviços inservíveis ou de produtos legalmente apreendidos, a quem oferecer maior lance, desde que igual ou superior ao previamente avaliado, sendo adotado, também, para a venda de bens móveis cuja aquisição tenha derivado de procedimentos judiciais.

\subsubsection{Pregão}

Criada mediante Medida Provisória ${ }^{\circ} 2.026 / 00$, o pregão visa a aquisição de bens e serviços comuns, qualquer que seja o valor estimado para a contratação, onde ocorre, durante a sessão, oferecimento de propostas e lances em sessão pública. Apenas em 17 de Julho de 2002, através da Lei Federal $n^{\circ} 10.520$, conforme disposto no artigo primeiro, fica instituído que "para aquisição de bens e serviços comuns, poderá ser adotada a licitação na modalidade de pregão, que será regida por esta Lei" (BRASIL, 2002). "Consideram-se bens e serviços comuns, para os fins e efeitos deste artigo, aqueles cujos padrões de desempenho e qualidade possam ser objetivamente definidos pelo edital, por meio de especificações usuais no mercado" (BRASIL, 2002). 
A divulgação de Pregões, o manual e o tutorial eletrônico, que ensinam o fornecedor a utilizar o sistema, estão disponíveis no Portal do site da UnC²

Cabe salientar que, de acordo com o inciso I do artigo quarto da lei 10.520/02,

\begin{abstract}
A convocação dos interessados será efetuada por meio de publicação de aviso em diário oficial do respectivo ente federado ou, não existindo, em jornal de circulação local, e facultativamente, por meios eletrônicos e conforme o vulto da licitação, em jornal de grande circulação (BRASIL, 2002).
\end{abstract}

O Portal de Compras esclarece que o pregão eletrônico permite que o fornecedor participe diretamente de seu computador. Durante o processo de credenciamento, o representante do fornecedor define uma senha que, após a aprovação do seu credenciamento, permitirá a participação nas compras eletrônicas. A proposta comercial poderá ser encaminhada online, no horário estipulado no Edital. Basta acessar o site e clicar no Pregão em andamento de interesse. Após a abertura das propostas, o pregoeiro fará análise do objeto e do preço ofertado para ver a conformidade com os requisitos estabelecidos no Edital. Depois que as propostas são aceitas, os valores são inseridos no sistema e todos os fornecedores tomam conhecimento dos preços, mas seus nomes não aparecem no sistema, o fornecedor é identificado por um número. A partir daí pode-se incluir lances e entrar na etapa competitiva. Todos os procedimentos são feitos online.

Os valores referenciais, conforme artigo 15 inciso $\mathrm{V}$ e parágrafo primeiro da lei 8.666/93, deverão balizar-se pelos preços praticados no âmbito dos órgãos e entidades da Administração Pública, bem como ampla pesquisa mercadológica. Para obtenção desses preços referenciais, não serão considerados menos de 3 (três) orçamentos colhidos no mercado ou em outros processos licitatórios do Poder Público.

\title{
2.1.7 Registro de Preços
}

Conforme Decreto $n^{\circ} 7.892$, de 23 de janeiro de 2013 - Art. $7^{\circ}$, a licitação para registro de preços será realizada na modalidade de concorrência, do tipo menor 
preço, nos termos da Lei $n^{\circ} 8.666$, de 1993 , ou na modalidade de pregão, nos termos da Lei $n^{\circ} 10.520$, de 2002, e será precedida de ampla pesquisa de mercado.

\subsubsection{Dispensa e Inexigibilidade de Licitação}

Bittencourt (2001), estrincha a "ausência" de licitação em 3 (três) conceitos distintos (Licitação Dispensada, Dispensável e Inexigível).

Licitação dispensada é aquela cuja realização é afastada pela própria lei, relacionada com a alienação de imóveis e móveis públicos. Licitação Dispensável é aquela em que existe uma desobrigação de instauração de procedimento licitatório, caso seja conveniente ao interesse público. Licitação Inexigível é aquela que existe inviabilidade de competição, diante do total de impossibilidade de confronto (BITTENCOURT, 2001, p. 60).

O artigo 24 da Lei 8.666/93, em seus 35 (trinta e cinco) incisos, estabelece os casos onde é razoável a dispensa de licitação, cabe salientar os incisos IV, V e XVII, onde fica estabelecido que a licitação é dispensável:

IV - nos casos de emergência ou de calamidade pública, quando
caracterizada urgência de atendimento de situação que possa ocasionar
prejuízo ou comprometer a segurança de pessoas, obras, serviços,
equipamentos e outros bens, públicos ou particulares, e somente para os
bens necessários ao atendimento da situação emergencial ou calamitosa e
para as parcelas de obras e serviços que possam ser concluídas no prazo
máximo de 180 (cento e oitenta) dias consecutivos e ininterruptos, contados
da ocorrência da emergência ou calamidade, vedada a prorrogação dos
respectivos contratos;
V - quando não acudirem interessados à licitação anterior e esta,
justificadamente, não puder ser repetida sem prejuízo para a Administração,
mantidas, neste caso, todas as condições preestabelecidas;
XVII - para a aquisição de componentes ou peças de origem nacional ou
estrangeira, necessários à manutenção de equipamentos durante o período
de garantia técnica, junto ao fornecedor original desses equipamentos,
quando tal condição de exclusividade for indispensável para a vigência da
garantia;

"Ao lado da dispensa de licitação, a inexigibilidade de licitação constitui exceção de que as obras, as aquisições e os serviços devem ser contratados mediante o processo licitatório" (TOLOSA FILHO; SAITO, 1995, p. 20). Os casos de inexigibilidade de licitação estão previstos no artigo 24 da lei $8.666 / 93$, onde é inexigível a licitação quando houver inviabilidade de competição, em especial: 


\subsection{BUROCRACIA}

"A organização burocrática é o tipo de sistema social dominante nas sociedades modernas; é uma estratégia de administração e de dominação; é fruto e berço da burocracia, com o qual inclusive por ser identificada" (MOTTA; BRESSERPEREIRA, 2004). Ainda segundo Motta e Bresser-Pereira (2004) um sistema social pode ser muito ou pouco organizado. Há sistemas sociais, como os pequenos grupos ou família, que têm grau de formalização da estrutura organizacional muito pequeno, quase inexistente. Um exército moderno, ao contrário, é um sistema social altamente organizado. Portanto, existem agrupamentos praticamente inorganizados e agrupamentos completamente organizados. À estes últimos chamamos de organizações burocráticas ou simplesmente burocracias.

Já Niebuhr (2013) argumenta que a licitação não é procedimento vazio, sem finalidade. Para o autor a licitação "serve não apenas para embaçar a atividade administrativa, mas ela é meio de celebrar o contrato administrativo de modo legitimo, sem corrupção, imoralidade ou favoritismo". Contudo, a lei nacional de licitações sempre recebeu muitas críticas, principalmente devido a generalização apresentada em seu texto, como também pelo rigor disposto nele, até mesmo pelo próprio autor. Como pode-se observar, até o ano de 2002 ela era a única legislação existente na regulamentação de compras públicas, diante disso, era aplicada tanto para a aquisição de um clips como para a construção de uma usina nuclear (SOUTO, 2012). Esse processo trazia morosidade e onerosidade para a Administração Pública ao realizar principalmente a contratação de bens e serviços comuns.

De acordo com Souto (2012), com o pregão eletrônico tentou-se romper com o excesso de formalismo, e para isso utilizou a inclusão de procedimentos 64 que possibilitaram o saneamento de documentos, propostas e atos, sem que para isso precisasse haver a anulação de processos. Além disso, com a inversão das fases, ou seja, a realização da habilitação dos documentos dos licitantes após a aceitação da proposta, fez com que o procedimento ganhasse agilidade. Soma-se a isso a utilização dos meios eletrônicos e da tecnologia da informação, não apenas para a divulgação e publicação dos atos, como também de todos os procedimentos, dando mais transparência a licitação. 


\subsubsection{Centralização e Descentralização}

Dentre os problemas discutidos no campo da Administração, talvez poucos têm sido motivo de tanta discórdia quanto o processo de centralização e descentralização nas empresas. Sabe-se que o administrador deve delegar autoridade, mas é extremamente complexo definir a medida exata e quais tarefas ou processos de decisão podem ser delegados. Motta e Bresser-Pereira (2004) ensinam que se as decisões de maior importância são tomadas na cúpula da organização, esta é centralizada. Seria descentralizada se boa parte dessas decisões coubesse a administradores mais abaixo na hierarquia organizacional.

Percebe-se que várias são as vantagens tanto da organização administrada de forma centralizada quanto de forma descentralizada. A decisão sobre centralização ou descentralização deve respeitar as características da organização, como, por exemplo, cultura organizacional, perfil dos profissionais envolvidos nos processos administrativos, fluxo de trabalho, aspectos legais, etc.

\subsection{ADMINISTRAÇÃO DE ESTOQUES}

Os estoques são materiais e suprimentos que uma empresa tem armazenado, seja para vender ou fornecer insumos ou para utilizá-los no processo produtivo. "Todas as empresas ou instituições precisam manter estoques. Frequentemente, os estoques constituem uma parte substancial dos ativos totais" (ARNOLD, 1999, p. 265). Segundo Martins e Alt (2006) os estoques têm a função de funcionar como reguladores do fluxo de negócios. Como a velocidade com que as mercadorias são recebidas são usualmente diferentes da velocidade com que são utilizadas, há necessidade de um estoque funcionando.

Quando a velocidade de entrada dos itens é maior que a de saída, ou quando o número de unidades recebidas é maior que o número de unidades expedidas, o nível de estoque aumenta. Se, ao contrário, mais itens saem (são consumidos), do que entram, o estoque diminui. E se a quantidade que é recebida é igual à que é despachada, o estoque mantém-se constante (MARTINS; ALT, 2006, p. 169). 
Assim sendo, mantidas as hipóteses de consumo e tempo de atendimento inalteradas, não existirão imprevisibilidades na demanda dos estoques. Entretanto, como obedecer a todas as hipóteses é difícil, é necessário que uma certa quantidade de itens fique em estoque para o caso como aumento inesperado do consumo, atraso nos pedidos ou na entrega dos produtos, etc. Nesse sentido (ARNOLD, 1999, p. 265) propõem a criação de um "estoque de segurança".

\subsubsection{Estoque de Segurança}

O estoque de segurança "é mantido com o propósito de atender a uma demanda que excede a quantidade prevista para um determinado período" (CHOPRA; MEINDL, 2003, p. 182). Segundo Arnold (1999),

\footnotetext{
Esse tipo de estoque é feito para cobrir flutuações aleatórias e imprevisíveis do suprimento, da demanda ou lead time. Se a demanda ou lead time são maiores que o esperado, haverá um esvaziamento do estoque. $O$ estoque de segurança é mantido para proteger a empresa dessa possibilidade. Sua finalidade é prevenir perturbações na produção ou atendimento aos clientes. Também é denominado de armazenamento intermediário ou estoque de reserva (ARNOLD, 1999, p. 269).
}

Em certos casos, o custo da falta de determinado item pode superar, em muito, o custo de se manter estoques. Em processos gargalos ou considerados vitais para a produção ou prestação de serviços, por exemplo, não seria considerado um custo desnecessário manter estoques para determinado item.

Chopra e Meindl (2003) ensinam que existem poucas chances de as previsões de demanda serem completamente precisas. Havendo os erros de previsão, a demanda real pode ser maior ou menor do que o previsto. Porém, conforme a variedade de produtos aumenta, o ciclo de vida destes encolhe. É bem provável que um produto moderno e atual hoje se torne obsoleto amanhã, principalmente diante das constantes inovações tecnológicas e mudanças de paradigma no mercado. 


\subsection{RELAÇÕES INTERNAS E EXTERNAS DO DEPARTAMENTO}

O departamento de compras mantém forte relacionamento com o público interno da instituição. Para esse departamento, são canalizadas todas as requisições de compras e as expectativas de pronto atendimento delas, funcionando como um setor assessor dos demais setores, considerando que para o funcionamento dos trabalhos desenvolvidos por estes, dependem de terem todas as ferramentas necessárias. Contudo para Dias e Costa (2003),

[...] essa função de assessor, não pode conduzir a posição de subordinação em relação às demais áreas. $A$ independência do departamento de compras é fundamental para garantir o desempenho esperado do setor de forma a trabalhar coesos na ação, mas independentes na decisão.

Algumas vezes podem ocorrer conflitos entre os anseios dos solicitantes e as limitações para a realização das aquisições. Nestes casos, é necessário, resolver os problemas, identificando os meios de satisfazer as solicitações dentro do que é estabelecido pelas normas e procedimentos das Universidades do sistema ACAFE.

\section{METODOLOGIA DO ESTUDO DE CASO}

O setor de compras das universidades inseridas no sistema ACAFE deverá ser responsável por todas as compras de materiais, bens e serviços, atendendo todos os setores das universidades.

Como sugestão, o departamento deverá ser constituído por um Gerente Geral de Compras, Assistentes e auxiliares divididos entre os Campi.

Como premissa o departamento desenvolverá todos os tipos de compras necessárias para as instituições, que são desde as compras de materiais mais simples como as de expediente, consumo e limpeza, até as mais complexas como as de construção civil, veículos, etc.

Os procedimentos de compras, deverão ser regidos de acordo com Instruções Normativas. 


\subsection{ORGANOGRAMA DO DEPARTAMENTO DE COMPRAS}

Figura 1 - Organograma do Departamento de Compras por categoria administrativa

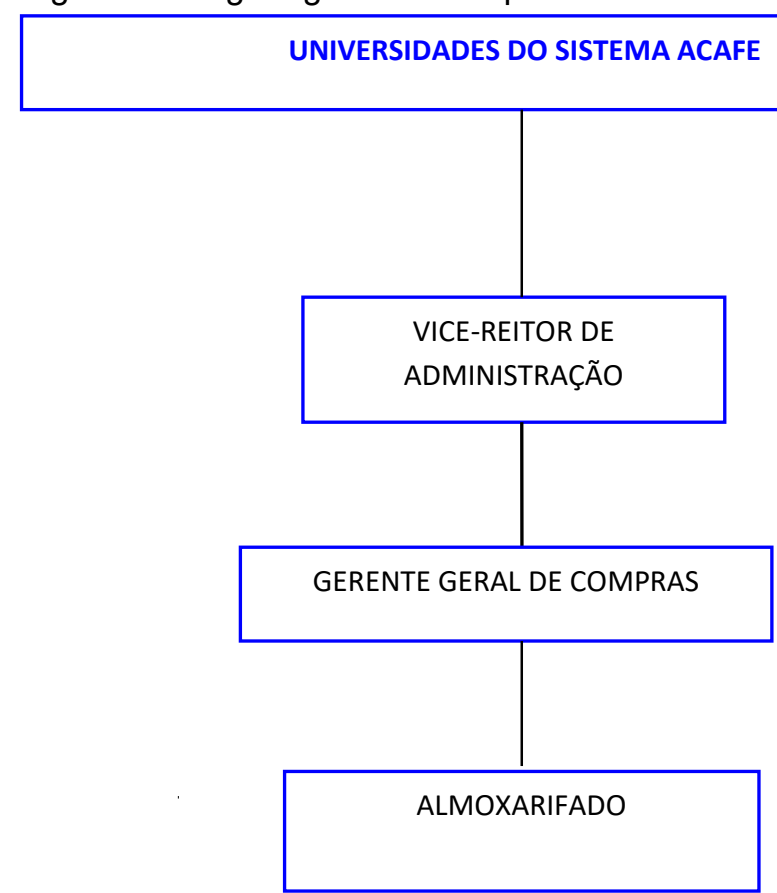

Fonte: Elaborado pelo autor (2019).

\subsection{RELAÇÕES INTERNAS E EXTERNAS DO DEPARTAMENTO}

As relações externas do departamento de compras são muito importantes, o bom relacionamento com os fornecedores e empresas contratadas é essencial para boas negociações. E importante também que o departamento esteja atento a novas tecnologias. 
A necessidade de padronização do processo de compras na Associação Catarinense das Fundações Educacionais (ACAFE)

Figura 2 - Relações internas por categoria administrativa

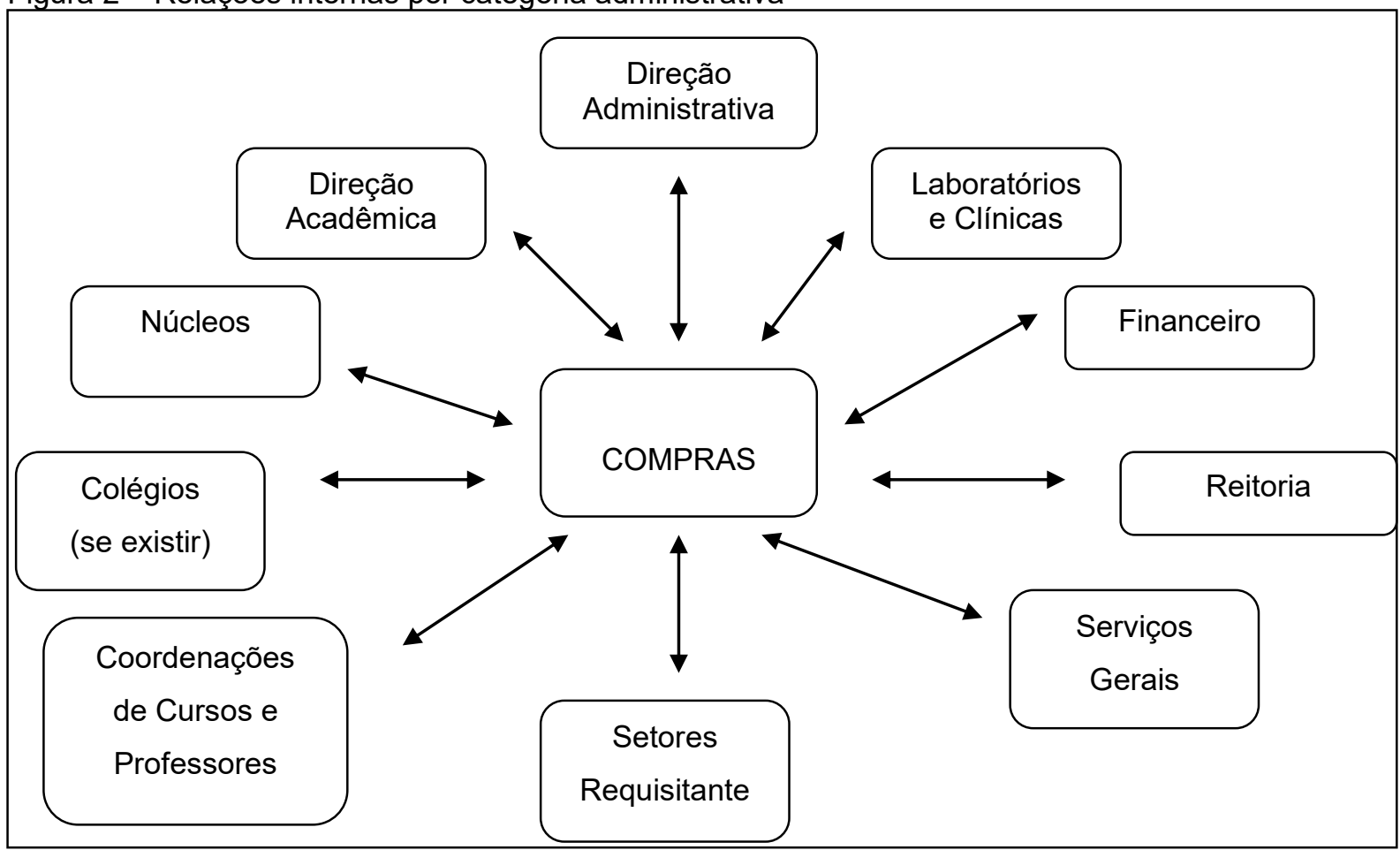

Fonte: Elaborado pelo autor (2019).

Figura 3 - Relações externas - Interferências nos resultados

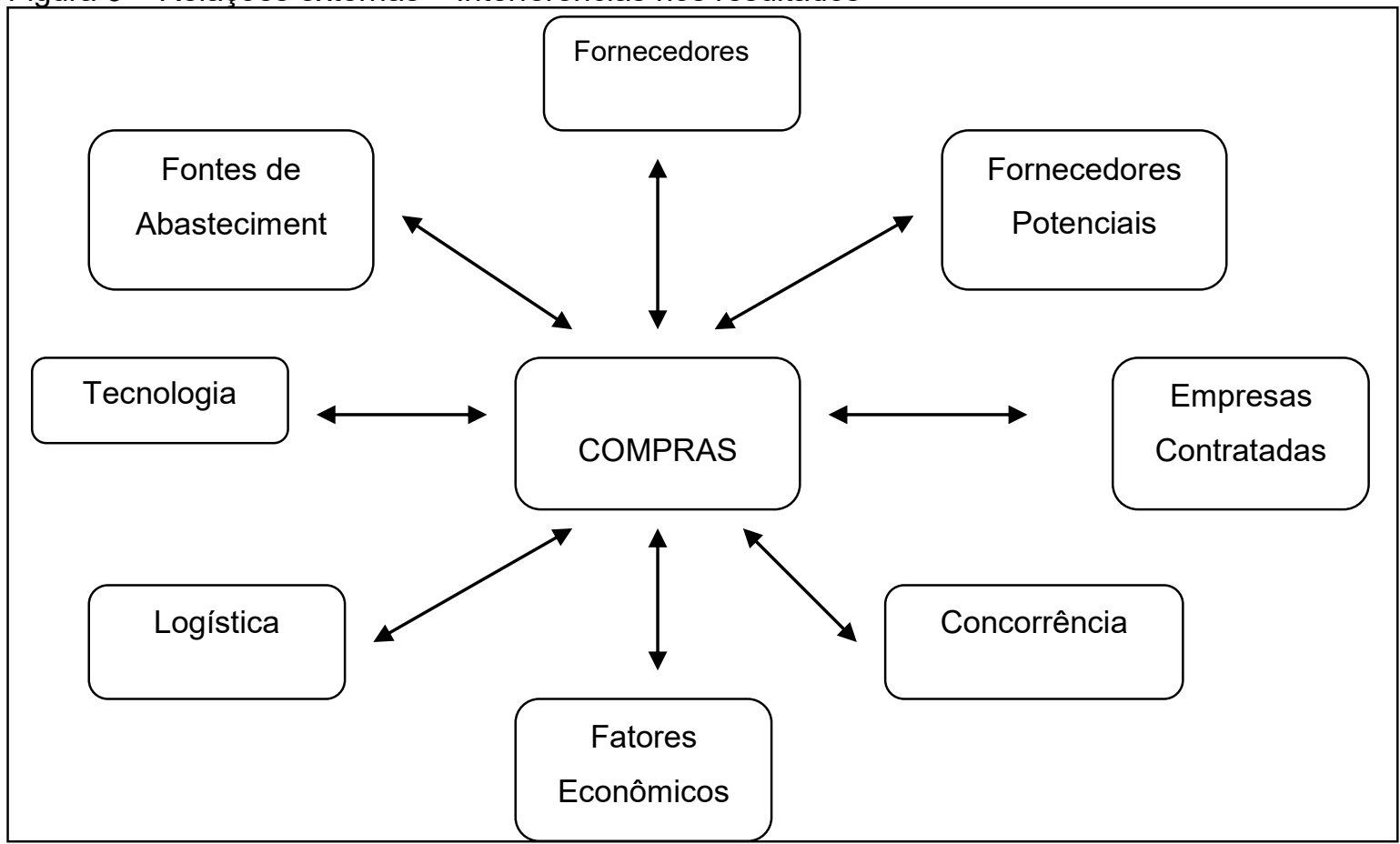

Fonte: Elaborado pelo autor (2019). 


\subsection{PROCEDIMENTOS PARA REQUISITAR MATERIAIS OU SERVIÇOS}

As instituições deverão ser organizadas em Centros de Custos (CC), assim como todos os setores das Universidades,

Serão disponibilizados loggins e senhas de acesso para preenchimento da Requisição de compras (RC), em sistema ERP, na qual deverá ser preenchida pelo requisitante descrevendo todas as especificações do produto/serviço com detalhes, quantidade e justificativa quanto à necessidade da aquisição. Em seguida a requisição deverá ser atestada pelo requisitante e pelo responsável pelo setor.

Após esse procedimento, as requisições deverão serem encaminhadas ao Central de Compras para a realização dos procedimentos e encaminhamentos conforme determinação expressa constante em Instruções Normativas.

\subsubsection{O Processo de Compras}

Após requisitado materiais ou serviços, o responsável pelo departamento de compras se encarrega de dar entrada ao processo de compra.

O primeiro passo será analisar a viabilidade da compra do material ou serviço solicitado. Esta avaliação deverá ser realizada pelo comprador e Vice-reitoria de Administração e Planejamento. No caso de parecer desfavorável tecnicamente a compra será suspensa, sendo previamente justificada a suspensão para o setor requisitante.

Com a RC autorizada, o comprador levantará possíveis fornecedores potenciais, em seguida contata os mesmos, repassando as informações necessárias sobre as características dos produtos ou serviços e definindo detalhes técnicos como prazos de entrega, tipo de frete, formas e prazos de pagamento, etc.

Coletados os orçamentos, o comprador passará a desenvolver a análise das propostas, observando todas as condições apresentadas com relação ao produto, ao valor, qualidade do material, prazos de entrega, garantias, tipo de frete, etc.

O fator predominante na escolha da melhor proposta será o valor dos itens, exceto em alguns casos especiais, como compra urgente, em que a escolha é feita pelo prazo de entrega. 
Após a análise e seleção da melhor proposta, deverá ser preenchida a ficha de cotação de preços em sistema ERP, em uma via, com a proposta de preço de todos, ou pelo menos três fornecedores e as características dos produtos ou serviços, quantidade, preço, prazo de entrega, tipo de frete, forma de pagamento, setor requisitante, etc., do fornecedor da proposta escolhida. Em seguida será emitida a Ordem de Compra em sistema ERP, em uma via. Nela consta o número do processo, as informações detalhadas em referencia ao produto, valor total da compra, quantidade a ser comprada, e os dados cadastrais do fornecedor com o qual será efetuada a compra.

O próximo passo será encaminhar o processo para procedimentos de verificação da disponibilidade financeira e novamente para análise e anuência da direção administrativa.

\subsubsection{Procedimentos de Conclusão de um Processo de Compras}

Antes de serem entregues aos requisitantes, os materiais adquiridos considerados duráveis, deverão ser encaminhados para registro de patrimônio departamento constante em cada unidade. $\mathrm{O}$ registro será realizado por pessoa responsável, que acopla no material um código de barras, que identifica todas as informações do material, podendo através dele saber o destino, a data que foi adquirida, o valor, o responsável, garantias, etc.

$\mathrm{Na}$ entrega do material ao requisitante, deverá ser conferido com o mesmo se o material comprado corresponde a sua solicitação, avaliando o seu grau de satisfação quanto à qualidade, o prazo para a efetivação do recebimento, etc. Esse acompanhamento é necessário para avaliar a eficiência do departamento.

Ainda serão necessários os procedimentos de pagamento e arquivamento do processo de compras, na qual haverá os setores Contas à Pagar e Contabilidade.

\subsubsection{Fornecedores}

A correta identificação dos fornecedores a serem consultados será etapa bastante importante para a obtenção das melhores condições comerciais para as organizações. 
A relação comprador/fornecedor precisa ser vista como um trabalho de parceria para que ambas as partes possam ser beneficiadas.

Os departamentos de compras das universidades, possuem carteiras estruturadas de fornecedores. Como os compradores trabalham muito através de email, tem-se os endereços dos fornecedores com os quais trabalha, no catálogo de endereços eletrônicos.

Os compradores, com suas vastas experiências, quando vai levantar um orçamento, já sabe quais fornecedores vai selecionar para enviar a solicitação de orçamento.

Os departamentos dispõem também de um amplo volume de catálogos para auxiliar na procura de fornecedores potenciais.

Como os materiais e serviços requisitados para os departamentos apresentam uma diversificação muito grande quanto à natureza de cada solicitação, muitas vezes encontra-se dificuldades para encontrar um fornecedor que se enquadre dentro das necessidades e exigências das instituições. Nestes casos, os compradores, no momento que recebe as requisições, já tenta levantar com o requisitante, possíveis indicações de fornecedores, supondo que o mesmo tenha maior conhecimento sobre o produto ou serviço solicitado, outra alternativa é fazer pesquisas na internet.

Em alguns casos, determinados fornecedores mantêm exclusividade no fornecimento de alguns materiais ou serviços, o que traduz uma preocupação constante em buscar novas alternativas de fornecedores ou materiais para evitar a dependência de único fornecedor.

Inúmeras vantagens podem ser citadas para o departamento quando há um número adequado de fornecedores para os itens necessários como: maior segurança, maior poder de negociação, preços competitivos, etc.

Os fornecedores devem ser qualificados para fornecer materiais e serviços para a instituição, de acordo com exigências pré-estabelecidas. Sendo necessários documentos que demonstrem algumas capacidades das empresas, inclusive para efeito de idoneidade, e para a garantia de fornecimento da compra como: Estatuto ou Contrato Social vigente, Inscrição no Cadastro Geral de Pessoas Jurídicas do Ministério da Fazenda (CNPJ), Inscrição Estadual e/ou Municipal, Referências Comerciais (em alguns casos), Negativas diversas e Outros. 


\subsubsection{Negociação}

A negociação não pode ser vista como uma disputa em que uma das partes ganha e a outra perde. Embora características de competição estejam obviamente ligados ao processo, quando ambas as partes saem ganhando, pode-se afirmar que ocorreu uma boa negociação.

Saber comprar é uma habilidade fundamental do profissional de compras. Algumas características são essenciais na hora da negociação:

-a preparação: estabelecer os objetivos e conhecer com clareza a natureza do material ou serviço a ser negociado pra mostrar firmeza e conhecimento ao vendedor;

-abertura: criar um clima de descontração, um "quebra-gelo";

-exploração: verificar se a necessidade detectada durante a etapa de preparação é verdadeira;

-apresentação: relacionar os objetivos e expectativas iniciais com a necessidade da outra parte;

-ação final: é a procura de um acordo ou decisão.

A equipe de compras deverá negociar' com seus fornecedores, menores custos, prazos de entrega, condições de pagamento, e outras quando necessário. Destaca a importância da cordialidade e bom relacionamento com os fornecedores como forma de tê-los como parceiros da universidade. Um bom entrosamento entre comprador e vendedor facilita a negociação e até outras contribuições como indicação de fornecedores potenciais. Lembra ainda, que a cordialidade e amizade, não pode significar interferência no processo de negociação e compra em si.

\subsubsection{O Almoxarifado}

Os almoxarifados são responsáveis por fornecer todo o material de expediente, consumo, limpeza, estocados para os setores das Universidades e recebimento, conferência e entrega dos materiais comprados. 
Para a retirada de materiais, os requisitantes deverão preencherem a Requisição de Material, devidamente atestada pelo responsável pelo setor. Com a entrega da requisição, os materiais poderão ser retirados no ato, ou, em caso do almoxarifado não dispor do material solicitado, encarrega-se de solicitar a compra e avisar o requisitante quando o material estiver disponível.

O almoxarifado deverá manter um estoque mínimo de todos os principais materiais de expediente, consumo, limpeza.

Entre as habilidades dos almoxarifados, estão a de recebimento, conferência e entrega dos materiais comprados pelo setor de compras, recebimento e lançamento das notas fiscais em sistema ERP para posterior pagamento e arquivo contábil.

\subsubsection{Principais Dificuldades na operacionalização dos departamentos}

Nos departamentos, devido principalmente a sua atividade intensa, conta com uma série de dificuldades que afetam diretamente o cotidiano de trabalho. Foram detectadas algumas dificuldades dos departamentos de compras das universidades:

-requisições de compras incompletas ou incorretas: os setores enviam requisições de compra sem especificações detalhadas das características dos materiais, ou com características erradas. A especificação do material deve identificar exatamente o desejado. A consequência de uma requisição dessa natureza, poderá causar a compra incorreta do material;

-compras com urgência: é frequente os departamentos de compras receber requisições de compras em caráter de emergência e cobrança excessiva dos requisitantes para a rápida aquisição. Compras com esse critério, não possibilitam muitas alternativas em termos de procura e de negociação, além de atrapalhar a programação do departamento;

-controle de entregas: os compradores precisam ficar atento com os prazos de entrega, precisando frequentemente entrar em contato com os fornecedores para cobrar entregas;

-falha dos fornecedores: demora para repassarem propostas, entregas incorretas, erro de nota fiscal, atraso de entregas; etc.; 
- grande mix de materiais: as compras vão de simples materiais do dia-adia, a complexas compras de materiais e serviços, como dizemos em nosso dia à dia, os compradores das universidades compram do alfinete ao foguete;

-fluxo excessivo de pessoas: o trabalho do comprador é constantemente interrompido pelos requisitantes. $O$ fluxo de pessoas que entram no departamento e a quantidade de ligações recebidas prejudica a concentração e trabalho;

- levar a proposta até o sistema ACAFE: provocar as lideranças do sistema ACAFE à fim de pautar a discussão e aprovação do presente tema junto às câmeras setoriais da ACAFE;

-quebra de paradigmas: as universidades inseridas no sistema ACAFE até então sempre exerceram suas atividades de forma peculiar e independente.

\section{CONSIDERAÇÕES FINAIS}

O objetivo principal do presente Artigo foi construído após se ter organizado o problema de pesquisa, o qual está consolidado na seguinte pergunta:

"Na atual conjuntura de estímulos à padronização e unificação do processo de Compras, as Normas e princípios à luz do Ordenamento Jurídico Brasileiro são suficientes para a aplicação nas Instituições de Ensino coligadas ao sistema ACAFE?

O autor do presente Artigo propõe a criação de uma Central Geral de Serviços de Compras, na qual deverá ser definida hierarquicamente através de uma possível assembleia ou indicação, tendo como premissa que todas as universidades do sistema ACAFE trabalharão e executarão as tarefas de forma única (seguindo como base Instruções Normativas).

Essa adequação será um tanto difícil, pois primeiramente deverá haver a tentativa em quebrar os paradigmas e particularidades de cada unidade, na qual até então, sempre exerceu suas atividades de forma peculiar e independente, dificultando assim inicialmente a emissão de relatórios e mantença do controle, pois os processos são operacionalizados de forma distinta. 
Após a adesão e concordância de todas as unidades, talvez, em alguns casos exigindo inclusive a contratação de novas pessoas, deverá ocorrer treinamentos in loco na sede da ACAFE tendo como objetivo o treinamento e habilitação dos compradores e almoxarifes.

O próximo passo será treinar e habilitar os requisitantes à trabalharem e solicitarem por meio de um sistema integrado os pedidos de compras.

1) Os processos deverão serem totalmente WEB, tanto no módulo material na qual controla o estoque dos materiais como no módulo compras;

2) As funções desempenhadas pelos compradores são extremamente importantes para os resultados da empresa. Uma das principais metas tendo como resultado do presente objeto, será a passagem da área de compras, antes estritamente operacional, para atividade de gestão, assumindo papel importante nas decisões da empresa.

Dias e Costa (2003), comentam "[...] que não podemos esquecer que até mesmo grandes guerras foram vencidas ou perdidas devido a melhor ou a pior atuação de suprimentos em seus momentos decisivos".

Ao desdobrar as etapas estabelecidas na tentativa de alcançar o objetivo geral da presente demanda, como primeira proposta específica foi "trazer para o cenário atual práticas nas atividades desenvolvidas e juntar aos estudos teóricos de apoio para a discussão a partir de Unidades de Análise como: Educação Tecnológica, Sociedade Comprometida com o Processo e a Ciência do Direito".

A escolha deste tema tão valoroso passou por diversas fases, as quais foram feitas e refeitas para se adaptar aos objetivos específicos do Artigo.

A prática das Compras Unificadas em todo o sistema ACAFE pode vir a ser um exemplo de aplicação em Políticas Nacionais na acepção da formação de atitudes, valores e habilidades que propiciem a performance individualizada e coletiva voltada para a identificação e a solução de problemas até então encontrados.

Vale destacar que, no momento conclusivo do presente Artigo, todos os procedimentos adotados no Estudo de Caso podem poupar energia dispendida e metodologias até então aplicadas em outras instituições de ensino. 
A abordagem jurídica normativa dado à análise das compras compartilhadas à serem realizadas pelas universidades do sistema ACAFE compreendem a originalidade e singularidade deste trabalho.

Para a materialização de todos os princípios até aqui descritos é importante que se passe da consciência pueril para um olhar um tanto crítico à ser aplicado por parte dos operadores, sejam eles pessoas jurídicas, privadas e públicas, transformando-se assim em realidade.

Caso ocorra a possibilidade de aplicação, procedimentos internos específicos e normas para a zelo das linhas de referência precisarão ser desenvolvidos pela Administração da ACAFE e pessoas envolvidas no processo.

No momento na qual as linhas de estudo sejam propostas e aplicadas nas Universidades que compõem o sistema ACAFE em futuros trabalhos via Gestores de Compras, como um item a ser discutido entre as diretorias executivas, então se terá condições de legitimá-las sob a ótica de benefícios ou não do antes e depois do estudo proposto.

\section{REFERÊNCIAS}

ARNOLD, J. R. Tony. Administração de materiais: uma introdução. São Paulo: Atlas, 1999.

BITTENCOURT, Sidney. Curso básico em licitação Lei n. 8.666/93, Lei 10.520/02 Lei Complementar n. 123/06. Rio de Janeiro: Revan, 2001.

BRASIL. Decreto $n^{0}$ 7.892, de 23 de janeiro de 2013. Regulamenta o Sistema de Registro de Preços previsto no art. 15 da Lei no 8.666, de 21 de junho de 1993. Disponível em: http://www.planalto.gov.br/ccivil_03/_Ato20112014/2013/Decreto/D7892.htm. 01 jun. 2019.

BRASIL. Lei 8.666, de 21 de junho de 1993. Regulamenta o art. 37, inciso XXI, da Constituição Federal, institui normas para licitações e contratos da Administração Pública e dá outras providências. Disponível em: http://www.planalto.gov.br/ ccivil_03/leis//8666cons.htm. Acesso em: 02 nov. 2017

BRASIL. Lei no 10.520, de 17 de julho de 2002. Institui, no âmbito da União, Estados, Distrito Federal e Municípios, nos termos do art. 37, inciso XXI, da Constituição Federal, modalidade de licitação denominada pregão, para aquisição de bens e serviços comuns, e dá outras providências. Disponível em: http://www.planalto.gov.br/ccivil_03/leis/2002/10520.htm. Acesso em: 01 jun. 2019. 
BRASIL. Medida provisória n².026, de 4 de maio de 2000. Institui, no âmbito da União, nos termos do art. 37, inciso XXI, da Constituição Federal, modalidade de licitação denominada pregão, para aquisição de bens e serviços comuns. Disponível em: http://www.planalto.gov.br/ccivil_03/mpv/Antigas/2026.htm. Acesso em: 01 jun. 2019.

BRASIL. Ministério da Economia. Portal de compras do governo federal:

comprasnet. Disponível em: http://comprasnet.gov.br/acesso.asp?url=/

ConsultaLicitacoes/ConsLicitacao_Filtro.asp. Acesso em: 22 set. 2019.

CHOPRA, Sunil; MEINDL, Peter. Gerenciamento da cadeia de suprimentos: estratégia, planejamento e operação. São Paulo: Prentice Hall, 2003.

DIAS, Marco Aurélio P. Administração de materiais: uma abordagem logística. 4.ed. São Paulo: Atlas, 1993.

DIAS, Mario; COSTA. Roberto Figueiredo. Manual do comprador: conceitos. técnicas e práticas indispensáveis em um departamento de compras. 3. ed. São Paulo: Edicta, 2003.

GARCIA, Giovani Ribeiro. A importância da função de compras nas organizações. Disponível em: https://www.outplan.com.br/a-importancia-da-funcaode-compras-nas-organizacoes/. Acesso em 22 set. 2019.

MARTINS, Petrônio G.; ALT, Paulo Renato Campos. Administração de materiais e recursos patrimoniais. 2. ed. São Paulo: Saraiva, 2006.

MEIRELLES, Hely Lopes; AZEVEDO, Eurico de Andrade; PRENDES, Célia Marisa. Licitação e contrato administrativo. 10. ed. atual. por Eurico de Andrade Azevedo São Paulo: Revista dos Tribunais, 1991.

MOTTA, Fernando C. Prestes; BRESSER-PEREIRA, Luiz C. Introdução à organização burocrática. 2. ed. rev. São Paulo: Pioneira Thomson Learning, 2004.

NIEBUHR, J. M. Licitação pública e contrato administrativo. 3. ed. rev. e ampl. Belo Horizonte: Fórum, 2013.

SISTEMA ACAFE. ACAFE. Disponível em: https://new.acafe.org.br/. Acesso em: 22 set. 2019.

SOUTO, M. J. V. Licitações e controle de eficiência: repensando o princípio do procedimento formal à luz do "placar eletrônico". In: ARAGÃO, A. S.; MARQUES NETO, F. A. Direito administrativo e seus novos paradigmas. Belo Horizonte: Fórum, 2012.

TOLOSA FILHO, Benedicto de; SAITO, Luciano Massao. Manual de licitações e contratos administrativos: comentários, modelos de editais, atas, recursos, decisões do Tribunal de Contas, citações da legislação paulista. Rio de Janeiro: Aide, 1995. 
A necessidade de padronização do processo de compras na Associação Catarinense das Fundações Educacionais (ACAFE)

Artigo recebido em: $17 / 12 / 2019$

Artigo aceito em: 18/02/2020

Artigo publicado em: 06/07/2020 